The influence of perceived credibility on purchase intention via competence and authenticity

Authors

Jong-Hyeong Kim, Ph.D. (Corresponding Author) School of Tourism Management, Sun Yat-sen University 135 Road Xin Gang Xi, Guangzhou, China, 510275 Email: jhkim96@gmail.com, Tel: +86-20-8411-4584; Fax: +86-20-8411-4569

Hanqun Song, Ph.D. Huddersfield Business School, Univeristy of Huddersfield, Queensgate, Hudderfield, HD1 3DH, West Yorkshire, UK Email: h.song@ hud.ac.uk June 30, 2020

Exclusively submitted to International Journal of Hospitality Management

* This work was supported by the National Natural Science Foundation of China for International Young Scholars (No. 71750110541). 


\title{
The influence of perceived credibility on purchase intention via competence and authenticity
}

\begin{abstract}
Due to the significant role of authenticity in the restaurant business, restaurateurs proactively make authenticity claims. However, the literature has rarely examined whether customers view these claims as credible and how the credibility of these claims influences dining intention. Thus, this study examines customers' perceived credibility of authenticity claims based on the authenticator claiming authenticity, restaurant ownership type, and restaurant history. Furthermore, utilizing trust-transfer theory, this study proposes and tests a model that links customers' perceived credibility of a restaurant's authenticity claims, perceived restaurant competence, perceived restaurant authenticity, and purchase intention. The results show that the authenticator of authenticity claims and restaurant ownership type influence the perceived credibility of authenticity claims. Additionally, the perceived credibility of authenticity claims influences customers' dining intention indirectly through restaurant competence and constructed authenticity.
\end{abstract}

Keywords: perceived authenticity, traditional foods, traditional restaurants, credibility, competence 


\section{Introduction}

Traditional restaurants that offer local cuisines, which reflect regional culinary cultures that have endured over generations (Vanhonacker et al., 2010), have become a growing market segment in the food service industry (Balogh et al., 2016). These enterprises serve as cultural disseminators promoting the uniqueness of local culture and heritage (Uggioni et al., 2010). Therefore, consumers' perceived authenticity of these restaurants (i.e., individuals' authenticity perceptions based on their created image of an object) is a determinant of their dining intention.

Accordingly, in an effort to increase customers' belief about restaurant authenticity, restaurateurs proactively claim that they are authentic through stickers or plaques posted outside the restaurant (Xu et al., 2015). However, Gilmore and Pine (2007) warned that businesses should not actively make self-authenticity claims because a self-labelled claim of authenticity declaring an authentic identity may lead consumers to doubt the credibility of the information. In support of this notion, Lehman et al. (2018) found that organizational self-claims about food authenticity decrease consumers' positive emotion, perceived overall restaurant authenticity, and value ratings toward a restaurant. This is a particularly important issue in China where a lack of trust and suspicion of credibility seem to have become a general phenomenon in contemporary society (He et al., 2012); consequently, consumers may doubt the credibility of organizational claims.

Therefore, as a means of increasing the credibility of authenticity claims, restaurateurs include additional information about their restaurant in their advertising materials such as who authenticated the restaurant (Xu et al., 2015); historical references (e.g., the age of the business); and background information (e.g., the business ownership type) (Blombäck and Brunninge, 2009). However, less is known about the effectiveness of these attributes on authenticity claims. 
According to signaling theory, markets are characterized by information asymmetry, which refers to different levels of product information possessed by firms and customers (Connelly et al., 2011). As information asymmetry causes customer uncertainty about the quality of a product, researchers suggest the use of appropriate signals, i.e., "an action that the seller can take to convey information credibly about unobservable product quality to the buyer" (Rao et al., 1999), to help customers reduce uncertainty about product or service quality. Therefore, it is critically important for traditional restaurateurs to utilize cues that enhance information credibility. Grounded in signaling theory, this study identifies appropriate signals (i.e., restaurant attributes) that enhance the perceived credibility of authenticity claims. To that end, this study specifically focuses on three attributes of restaurants - authenticators, history, and ownership type-because they are widely used to exhibit the trustworthiness and expertise of advertisers, which are important properties of credibility (Spry et al., 2011).

Acknowledging the significant effect of credibility on consumer behavior, researchers have examined the impact of the credibility of various cues on consumer behavior, such as advertising (Lohse and Rosen, 2001), health claims and nutrition information (Kozup et al., 2003; Lee et al., 2015), and online reviews (Filieri, 2015; Filieri et al., 2015; Mauri and Minazzi, 2013). However, a research gap found in the extant credibility literature is the lack of a theoretical model explaining the mechanism by which information credibility affects consumer behavior. Trust-transfer theory suggests that individuals' trust in one trustable entity could influence another unknown target (Stewart, 2003). Accordingly, previous studies employing trust-transfer theory mainly focused on the trust-transfer to a different context or unknown entity, such as from vendors to retailers (Ganesan, 1994), a company's web services to its mobile services (Wang et al., 2013), and a retailer's offline operations to online operations (Kuan and 
Bock, 2007).

However, research shows that trust-transfer may also occur within the same entity. For example, Lowry et al. (2007) found that the credibility of third-party logos on a website significantly influenced trust of the website. In support of this finding, Filieri (2015) reported that perceived source credibility of online reviews positively influences trust toward the website. Therefore, this study extends the trust-transfer theory by examining the trust transfer within the same service organization. Specifically, customers' perceived authenticity, which refers to individuals' subjective beliefs about a restaurant's authenticity, is the main construct determining the value and quality of service offerings in this study context (Beverland et al., 2008; Castéran and Roederer, 2013). Furthermore, competence, which is an important dimension of trust (Wang et al., 2014), denotes an organization's knowledge, resources, skills, and abilities to realize promises (Prahalad and Hamel, 1990; Spencer and Spencer, 2008). Thus, employing trusttransfer theory to elucidate the mechanism by which credible authenticity claims influence consumer behavior could complement signaling theory in predicting dining intention at a traditional restaurant.

In summary, this study addresses the above unexplored issues by focusing on Chinese domestic tourists' dining behavior at a traditional restaurant. The purpose of this study is 1) to examine how restaurant attributes influence the credibility of authenticity claims and 2) to present and test a conceptual model that expands our understanding of information credibility and its consequences in a traditional dining setting.

\section{Literature review}




\subsection{Authenticity claims as a signal}

Signaling theory was developed by Spence (1974) who theorized in information economics that different levels of product information flow between customers and service organizations. Thus, customers often face an information deficit, which hinders their ability to distinguish service organizations offering high-quality products from those offering low-quality ones. A solution to this asymmetric information environment is for a business to send signals that help consumers evaluate product quality (Atkinson and Rosenthal, 2014).

To date, limited research applying signaling theory could be identified in the tourism and hospitality literature. Filieri et al. (2020) are the first to apply the signaling theory in the tourism literature. By focusing on negative tourism reviews, these authors analyzed three types of product quality signals affecting review helpfulness, including traditional product quality signals (e.g., hotel category and affiliation with a brand chain), user-generated product quality signals (e.g., review volume and average rating score), and third-party product quality signals (e.g., a certificate of excellence), and confirmed that product quality signals affect consumer evaluations of extremely negative judgments.

In this study's context, signals are information sent from traditional restaurants to customers to communicate information about restaurant authenticity. Researchers have examined the effectiveness of various signals (i.e., authenticity cues) that produce authentic feelings and images of a restaurant; such signals include food (De Vries and Go, 2017; Kim and Jang, 2016; Kim et al., 2017), environment and atmosphere (De Vries and Go, 2017; Tsai and Lu, 2012), and social factors in terms of other customers and employees (De Vries and Go, 2017; Kim and Jang, 2016; Song et al., 2019; Wang and Mattila, 2015). The findings of these previous studies can guide restaurateurs who emphasize authenticity in their businesses. 
However, there is a lack of research examining the effect of advertising claims on consumer behavior. Gilmore and Pine (2007) noted that individuals are heavily exposed to authenticity advertising. Authenticity claims are increasingly common in the restaurant context where businesses are eager to distinguish their products and services as authentic. Furthermore, restaurateurs expect the potential benefits of promoting their products and services as authentic, yet many customers remain unconvinced about the truthfulness of authenticity claims (Gilmore and Pine, 2007). Boulding and Kirmani (1993) noted that when the credibility of signals is doubtful, customers are unlikely to rely on them as important information cues. Therefore, this study focuses on three attributes that are widely used in practice, and it examines the influence of those attributes on the credibility of authenticity claims.

\subsection{Credibility of authenticity claims and restaurant competence: signaling theory and trust-} transfer theory as underpinning theories

Studies have identified credibility as a trust dimension (Doney and Cannon, 1997) and have defined it as the extent to which a receiver considers the believability level of information (Wathen and Burkell, 2002). Researchers have expanded the concept of credibility to other constructs such as source credibility (Filieri, 2016; Filieri et al., 2015) and message credibility (Filieri, 2016; Hu and Sundar, 2010; Tormala and Petty, 2004). In the online review context, consumers can easily distinguish these two types of credibility. For instance, source credibility relates to reviewers, whereas message credibility relates to the content of online consumer reviews (Filieri, 2016). However, for offline information such as stickers outside restaurants, consumers may consider that the stickers were produced by the restaurants themselves; thus, it is unlikely that consumers can distinguish source credibility from message credibility. Therefore, in 
line with McGinnies and Ward's (1980) study, this study merges source credibility and message credibility to assess the credibility of authenticity claims. Signaling theory emphasizes the credibility of signals, suggesting that effective signals work only to the extent that customers perceive them as credible (Boulding and Kirmani, 1993). Thus, the credibility of authenticity claims is a key concept in this study.

Trust-transfer theory suggests that once the credibility of authenticity claims is achieved, an individual's trust in a target can shift to other related targets (Doney and Cannon, 1997). According to Stewart (2003), trust transfer occurs through two different processes: the cognitive process and the communication process. Through the cognitive process of trust transfer, the initial trust in an entity can be transferred to an unknown target based on the understanding of the relationship between the trusted entity and the target (Liu et al., 2018). For example, patients' trust in an original hospital significantly influenced their trust in its allied hospitals because they could perceive the business relationships and similarities between the two organizations (Lien et al., 2014). Similarly, utilizing trust-transfer theory, Lee et al. (2014) explained the impact of a mega event on visitors' attitudes toward the hosting destination. However, the communication process of trust transfer occurs when the trustor is influenced by others through communication and social interaction (Kuan and Bock, 2007). For example, if an individual receives positive comments on a target from a trusted person, he or she is more likely to establish trust in the target. Both perspectives of the trust-transfer theory are used in this study to propose and test a conceptual model. More specifically, the communication mechanism is used to explain the effect of restaurant cues (signals) on consumers' perceived credibility of authenticity claims, and the cognitive mechanism is adopted to explain the effect of consumers' perceived credibility of authenticity claims on perceived restaurant competence and their subjective beliefs about 
restaurant authenticity.

Researchers have defined competence as an organization's knowledge, resources, skills, and abilities to realize promises (Prahalad and Hamel, 1990; Spencer and Spencer, 2008) and as an important dimension of trust (Wang et al., 2014). For example, trust is often referred in terms of customer confidence or the willingness to rely on a trustee's competence and reliability (Johnson and Grayson, 2005; Morgan and Hunt, 1994). In support of this conjecture, Spencer and Spencer (2008) noted that competence captures a person's (or organization's) knowledge in specific content areas and a person's (or organization's) ability to perform a specific task. Due to this specificity, researchers have usually examined a specific type of competence such as online competence (Kim et al., 2013), e-commerce competence (Hong and Cho, 2011), and riskmanagement competence (Williams and Baláž, 2013). Accordingly, this study focuses on a restaurant's competence of delivering authentic food and experiences in a traditional setting.

\subsection{Perceived authenticity}

Authentic restaurants are narrowly defined as restaurants that serve authentic dishes (Strohl, 2019). However, authentic restaurants can broadly refer to any restaurant with two key features including essential features (e.g., local ingredients, traditional recipes, personal attention, and well-behaved employees) and peripheral features (e.g., good food quality, restaurant name, external façade, homely feeling, presenting food as art, interior, surroundings, and regular changes to menu) (De Vries and Go, 2017). As a restaurant's authenticity is subjective (Grayson and Martinec, 2004), the following discussion addresses how customers develop authenticity perceptions.

Taylor (1991, p.17) defined authenticity as "that which is believed or accepted to be 
genuine or real"' The tourism and hospitality literature has three authenticity research streams: objective, constructive, and existential. Objective authenticity relates to facts (Sims, 2009) and whether an object is true (Kovács et al., 2017). Thus, "inauthentic objects yield inauthentic experience, and no copy could ever be authentic" (Rickly-Boyd, 2012, p. 87). Constructive authenticity comprises individuals' social beliefs, expectations, preferences and perceptions (Peterson, 2005). Different customers may have different interpretations of the authenticity of an object based on their own beliefs, expectations or perceptions (Kovács et al., 2017). Finally, existential authenticity relates to achieving a personal and intersubjective state of the authentic self (Wang, 1999). Existential authenticity mainly concerns customers' authentic selves rather than the authenticity of a restaurant.

Although these three types of authenticity can to some extent be applied in the traditional restaurant context, researchers emphasize constructive viewpoints in studying consumers' perceived authenticity (Kim and Jang, 2016; Ma et al., 2017). They argue that what consumers perceive as authentic must conform to their mental frames of how things 'ought to be' (Grayson and Martinec, 2004). Thus, this study examines customers' perceived authenticity, which is operationally defined as customers' subjective belief that they will have an authentic dining experience in a restaurant. This implies that the successful delivery of restaurant authenticity is dependent on the use of effective cues that reflect the characteristics of authenticity.

\subsection{Influences on the perceived credibility of authenticity claims}

\subsubsection{Role of the authenticator}

In the literature, authenticators are persons or organizations that authenticate objects (Mkono, 2013; Peterson, 2005). Lugosi (2016) stated that multiple actors play a role in 
authenticating authenticity. For example, the government has the power to authenticate tourist attractions (e.g., heritage sites) based on scientific or historical endorsements and facts (Cohen and Cohen, 2012). Furthermore, the local community plays a role in authenticating tourist objects (Lugosi, 2016); for instance, it has the freedom to authenticate restaurants and hotels online and offline through word-of-mouth. Additionally, businesses' self-claims of authenticity have recently become popular (Kovács et al., 2017).

However, consumers are typically skeptical of businesses' self-promotional activities (Boush et al., 1994) and have an unfavorable attitude toward them (Hoorens et al., 2012). Haley (1996) also discussed how nonprofit sources (e.g., government and local community) are considered more credible than commercial sources (i.e., businesses). This discussion leads to the following hypothesis:

H1: A traditional restaurant's self-authentication negatively influences the perceived credibility of the restaurant's authenticity claims.

\subsubsection{Role of restaurant ownership type}

Independent restaurants and chain restaurants are two typical restaurant ownership formats. Chain restaurants are multiunit enterprises that are owned or operated by a single company with a similar look, menu, and décor; by contrast, independent restaurants are independently owned and small (Lee et al., 2016) and are often unique in terms of their look and menu (Harris et al., 2014).

Source credibility theory defines source credibility as the perceived believability of a sender (O'Keefe, 2002). Both an independent restaurant and a chain restaurant can be defined as 
a sender. Compared with independent units, chain organizations enjoy widespread recognition and familiarity (Carroll and Torfason, 2011), which lead to consumers' trust towards chain organizations (Komiak and Benbasat, 2006). In addition, customers assess whether the messages delivered in advertisements are accurate and whether the message source is credible (Folkes, 1988). Thus, consumers are likely to believe chain restaurants to be more credible than independent restaurants. Source credibility can directly form or change a receiver's attitude, and the information provided by a highly credible source will have a greater effect on perceived information credibility (Luo et al., 2013). According to the trust-transfer theory, trust can be transferred from a source, which in this study is the restaurant, to the claims made by the restaurant. In line with this discussion, the following hypothesis is presented:

H2: Restaurant chain ownership positively influences the perceived credibility of a restaurant's authenticity claims.

\subsubsection{Role of the history of a restaurant}

Every firm has a history. A short history reflects newness whereas a long history reflects continuity or endurance (Blombäck and Brunninge, 2009). A long history also shows the ability of a business to keep its promise that it will continue to deliver on its quality commitments (Wiedmann et al., 2011). Thus, a brand with a long history is associated with characteristics such as being credible, trustworthy, familiar, secure, and reliable (Chang and Tung, 2016).

Furthermore, researchers have suggested that restaurants' history significantly affects customers' perceived restaurant authenticity (Sinha et al., 2018). Accordingly, the authenticity of 
traditional cuisine is often portrayed by the stereotypical image originating in the "good old days" (Scarpato and Daniele, 2003). Thus, when a traditional restaurant that has a long history of operation makes authenticity claims, customers are more likely to believe these claims.

Accordingly, this study proposes the following hypothesis:

H3: A restaurant with a long history positively influences the perceived credibility of its authenticity claims.

2.5. Relationships among the credibility of authenticity claims, perceived competence, perceived authenticity, and purchase intention

\subsubsection{Credibility of authenticity claims and purchase intention}

The literature consistently reports a positive relationship between advertising credibility and purchase intention. For example, Lafferty et al. (2002) and Lim and Van der Heide (2015) found that the credibility of advertisements is a key factor determining purchase intention. In the hospitality setting, Kim and Kim (2014) found that the source credibility of green messages influences visit intention at a green hotel. Based on the above literature, this study proposes the following hypothesis:

H4: The perceived credibility of authenticity claims positively influences purchase intention.

\subsubsection{Credibility of authenticity claims and perceived competence}

As discussed above, trust is transferred from one trusted entity to another unknown 
entity. Although there is a lack of empirical studies testing this theory in the tourism and hospitality literature, some tourism researchers have found positive relationships among trust in different entities in the Internet environment. For example, Filieri (2016) adopted a qualitative approach to study the various factors referring to the source, content, message framing and message order in consumers' perception of online review trustworthiness. Filieri et al. (2015) used a quantitative approach to investigate the influence of source credibility, information quality, website quality, customer satisfaction, and user experience on trust towards consumer-

generated media (e.g., Tripadvisor and Airbnb) and its consequences on consumer behavior, such as e-word-of-mouth and information adoption. Both studies show that the credibility of review messages facilitates individuals' trust that a website provides sincere and trustworthy information. Similarly, if consumers perceive a restaurant's authenticity claims to be credible, they will believe that the restaurant has the capability and resources to deliver the promised food and experience. This leads to the following hypothesis:

H5: The perceived credibility of a restaurant's authenticity claims positively influences the perceived competence of the restaurant.

\subsubsection{Credibility of authenticity claims and perceived authenticity}

The brand literature has noted that brand credibility is crucial for the development of brand authenticity. For example, Morhart et al. (2015) and Portal et al. (2018) observed that brand credibility is a key component of brand authenticity: higher credibility leads to a higher level of brand authenticity. If individuals perceive a restaurant's authenticity claims as credible, then they will be likely to believe that the restaurant is authentic. This leads to the following 
hypothesis:

H6: The perceived credibility of a restaurant's authenticity claims positively influences the perceived authenticity of the restaurant.

\subsubsection{Restaurant competence and purchase intention}

The research has confirmed the causal relationship between competence and behavioral intentions. For example, Kervyn et al. (2012) demonstrated that high-competence brands generate a higher consumer purchase intention than low-competence brands. Comparing the effect of two firm characteristics (i.e., competence and warmth) on consumers' purchase intention, Aaker et al. (2010) and Aaker et al. (2012) verified that the perceived competence of firms is a direct driver of consumers' purchase intention, indicating the significant role of competence in determining consumers' purchase intention. Consistent with this discussion, this study hypothesizes the following:

H7: Restaurant competence positively influences purchase intention.

\subsubsection{Restaurant competence and perceived authenticity}

Brand management researchers suggest that customers' evaluations of an authentic brand are based on the brand's ability and skills to fulfill its quality commitments (Beverland, 2005; Moulard et al., 2015). For example, focusing on the brand authenticity of wines, Beverland (2005) found that the talent and skills needed for production quality are crucial to conveying a feeling of authenticity. In this study, restaurant competence is related to a restaurant's ability and 
resources to deliver an authentic experience or food. In corroborating the literature, if consumers perceive that a restaurant has sufficient ability and resources to deliver an authentic experience or food, then they will be likely to believe that the food and experience are authentic. This leads to the following hypothesis:

H8: Restaurant competence positively affects consumers' authenticity perception.

\subsubsection{Perceived authenticity and purchase intention}

The literature has well documented the significant influence of perceived authenticity on purchase intention. For example, focusing on food-related and socially related ethnic cues, researchers have found that constructed authenticity directly affects customers' purchase intention (Kim and Baker, 2017; Wang and Mattila, 2015; Youn and Kim, 2017). Specifically, Youn and Kim (2017) found that the perceived authenticity formed by the authentic characteristics of ethnic food significantly affect customers' purchase intention for ethnic Chinese food. In support of this finding, Kim and Baker (2017) confirmed that perceived authenticity determines revisit intention and the willingness to pay more. This discussion leads to the following hypothesis:

H9: Perceived authenticity positively influences purchase intention.

In summary, based on the theoretical background discussed above, this study proposes nine hypotheses to identify credible authenticity claims for traditional restaurants and to explain the effects of such claims (see Fig. 1). 
[Insert Fig. 1. here]

\section{Materials and methods}

\subsection{Design and stimulus selection}

This study employed a 3 (authenticator: government versus local community versus business) by 2 (ownership type: an independent unit versus a chain) by 2 (history: short versus long) between-subjects design. Crossing the experimental factors resulted in 12 conditions. The stimuli are shown in Appendix 1. The participants were asked to read the description of a traditional restaurant. They were then asked to evaluate the restaurant. The participants' perceived credibility of the restaurant's authenticity claims, perceived restaurant competence, and perceived restaurant authenticity as well as the participants' purchase intention were measured for all experimental groups.

\subsection{Measures}

The items for the four constructs - perceived credibility, perceived competence, perceived authenticity, and purchase intention-were adapted from the literature. Specifically, five items on perceived credibility were developed from Filieri (2015) and Holbrook (1978); three items on perceived competence were adapted from Hong and Cho (2011); five items on perceived authenticity were selected from Meng and Choi (2017) and Wang and Mattila (2015); and three items on purchase intention came from Lu et al. (2015) and Wang and Mattila (2015). The participants responded to all items on 7-point bipolar scales (disagreeable [1]-agreeable[7]). 
In addition, manipulation checks were conducted for three independent variables. For authenticators, the respondents were asked to indicate who authenticated the restaurant (government, local people, and business). The other two manipulated variables (i.e., this restaurant is a chain restaurant, and this restaurant has a long history) and the realism of the stimuli (i.e., this traditional restaurant is realistic) were measured on 7-point bipolar scales (disagreeable [1]- agreeable [7]).

To determine the underlying dimensionality of credibility, the researchers performed exploratory factor analysis (EFA) for the five items using varimax rotation. Consistent with McGinnies and Ward's (1980) theorization, the results confirmed a unidimensional scale loading the following items: the source of the claim is "trustworthy," "reliable," and "convincing," and the claim is "likely to be true" and "believable". These items explained $64.43 \%$ of the total variance. The scale mean was used to assess each construct.

\subsection{Preliminary study}

The researchers conducted a preliminary study to check the manipulation control for the three independent variables, to assess the realism of the scenario, and to determine the number of years for a short and a long history. Some time-honored restaurants in China have a long history of more than 250 years (Gao and Wang, 2012); in contrast, some new traditional restaurants started in the 1990s. Thus, restaurant history was initially manipulated using 25 years and 200 years.

This study recruited 143 participants from a Chinese panel data company (Baidu Mobile Testing Centre, 2019) and confirmed the effective manipulation of the authenticator, ownership type and history. For example, a chi-square contingency table analysis showed a significant 
association between the authenticator manipulation in the scenario and the respondents' perceived authenticator $\left(\chi^{2}(4, N=143)=286, p<.001\right)$. Furthermore, Mann-Whitney tests showed that the manipulation for both the history $(\mathrm{Z}=3.662, p<.001)$ and ownership conditions $(\mathrm{Z}=4.240$, $p<.001)$ was successful. Additionally, the participants reported high mean ratings on the realism check $(\mathrm{M}=5.39, \mathrm{SD}=1.46)$.

\subsection{Procedures and participants}

The main data collection was performed by the Department of Panel Data Collection of Baidu in China, which is an online survey service company providing panel data collection services. The experimental stimuli and the survey questionnaire were sent to randomly chosen Chinese consumers in Guangdong Province. A screening question about previous dining experiences at a traditional restaurant (i.e., have you dined in a time-honored restaurant before?) was utilized. Before the participants answered the survey questions, the system randomly allocated eligible respondents to one of the 12 versions of the scenario provided at the beginning of the questionnaire. The total number of targeted responses was 480 (40 subjects per experimental condition).

This study collected 411 valid responses, with a cell size of 34-35. The percentage of males (51.8\%) was slightly larger than that of females (48.2\%). A total of 50.4\% of the respondents were aged 55 or over, and $49.6 \%$ were aged $18-30$. The majority of the participants had a high school diploma (36.1\%) or a university degree (35.9\%). The top three occupations were retired (16.9\%), white collar (13.5\%), and professional (10.6\%). Furthermore, approximately $40 \%$ of the sample had an income of RMB3000-7000, indicating that the study participants had relatively high monthly incomes. 


\subsection{Data analysis}

The researchers conducted a three-way analysis of covariance (ANCOVA) with perceived credibility as the dependent variable and the authenticator and ownership type and history as the independent variables. The participants' age was controlled because Kong et al. (2009) found a correlation between participants' age and their preferences for time-honored brands in China. The proposed structural model was tested based on the suggestion by Anderson and Gerbing (1988), and a confirmatory factor analysis (CFA) was performed before testing the structural model.

\section{Results}

\subsection{Manipulation check}

In the main study, the manipulation controls were effective. The respondents recognized the projected authenticator in the scenario $\left(\chi^{2}(4, N=411)=822, p<.001\right)$. Additionally, MannWhitney tests showed that the manipulation for both history $(\mathrm{Z}=5.248, p<.001)$ and ownership conditions $(\mathrm{Z}=6.965, p<.001)$ was successful. Finally, the respondents regarded the scenarios as realistic $(\mathrm{M}=5.52, \mathrm{SD}=1.13)$.

\subsection{Effect of the authenticator, ownership type, and history on the credibility of authenticity} claims

Table 1 shows the ANCOVA results for the credibility of authenticity claims. The covariate was found to be significant (age, $F[1,398]=30.227, p<.001$ ). The authenticator $(F[2,398]=8.716, p<.01)$ had a significant main effect on customers' perceived credibility of 
authenticity claims. Specifically, business self-claims had a significantly lower score on perceived credibility than government and local community claims $\left(M_{\text {government }}=5.107, M_{\text {local }}\right.$ community $=5.022, M_{\text {business }}=4.631$ ). As a result, $\mathrm{H} 1$ is supported.

The main effect of ownership type $(F[1,398]=5.996, p<.05)$ on customers' perceived credibility of authenticity claims was significant. In particular, chain restaurants had a significantly higher perceived credibility score than independent restaurants $\left(M_{\text {chain }}=5.042\right.$, $\left.M_{\text {independent }}=4.798\right)$. Therefore, $\mathrm{H} 2$ is confirmed. However, the main effect of history on the credibility of authenticity claims was not significant. Consequently, H3 is rejected.

[Insert Table 1 here]

In addition to the main effects described above, this study found an interaction effect between the ownership type and history of traditional restaurants on customers' perceived credibility of authenticity claims $(F[1,398]=4.142), p<.05)$. As shown in Fig. 2, in the 25-year condition, there were significant differences between independent and chain restaurants in terms of the credibility of authenticity claims $\left(M_{\text {chain }}=5.157, M_{\text {independent }}=4.709, t[406]=9.822, p<.01\right)$; however, in the 250-year condition, there were no significant differences $\left(M_{\text {chain }}=4.929\right.$; $M_{\text {independent }}=4.880, t[406]=.116$, n.s. $)$.

[Insert Fig. 2 about here] authenticity, and purchase intention 


\subsubsection{Measurement model}

The CFA results indicated that the measurement model fit the data well: goodness-of-fit index: $\chi^{2}=194.96, d f=98, \chi^{2} / d f=1.99, \mathrm{CFI}=.971, \mathrm{TLI}=.965, \mathrm{IFI}=.972, \mathrm{RMSEA}=.049$. Both Cronbach's alpha values (ranging from .82 to .86) and the composite reliability scores (ranging from .82 to .86 ) of the study constructs indicated adequate internal consistency (i.e., >.7). Hair et al. (2010) suggested that all factor loadings should exceed the minimum level of .50 to represent convergent validity.

As shown in Table 2, all measurement items had significant loadings (values ranging from .70 to .81). Furthermore, the average variance extracted (AVE) for all constructs exceeded the recommended threshold of .50 , ranging from .53 to .61 . This result indicated convergent validity. In the next step, this study confirmed discriminant validity by comparing the squared correlations between the constructs and the AVE values (Fornell and Larcker, 1981). As shown in Table 3, all squared correlations between the paired constructs were lower than the intended AVE estimates.

[Insert Table 2 here]

[Insert Table 3 here]

\subsubsection{Modeling comparisons and structural equation model}

To test the current research model, the researchers ran a series of nested models and compared model fit. For example, the researchers compared a full mediation model $\left(\chi^{2}=165.070\right.$, $\left.d f=98, \chi^{2} / d f=1.684, \mathrm{CFI}=.980, \mathrm{NFI}=.953, \mathrm{IFI}=.980, \mathrm{TLI}=.976, \mathrm{RMSEA}=.041\right)$, which $\operatorname{did}$ not have a direct causal path from the credibility of authenticity claims to purchase intention, with a 
research model that included the direct path $\left(\chi^{2}=160.287, d f=97, \chi^{2} / d f=1.652, \mathrm{CFI}=.981\right.$, $\mathrm{NFI}=.954, \mathrm{IFI}=.981, \mathrm{TLI}=.977, \mathrm{RMSEA}=.040$ ). The chi-square difference between the two models was significant $\left(\Delta \chi^{2}(1)=4.783, p<.05\right)$.

To further verify the importance of each mediator, the researchers tested a series of nested models against the research model through $\chi^{2}$ tests. In alternative model 1 , the path related to H6 was constrained to zero. Additionally, the researchers constrained the path related to H4 and H6 in alternative model 2. A significant chi-square difference would suggest that the constrained paths are important and thus provide support for the research model. As shown in Table 4, all chi-square differences were significant, supporting the hypothesized mediated relationships in the research model.

[Insert Table 4 here]

The proposed causal relationships were tested using PROCESS as described by Hayes (2013). The results showed significant effects (i.e., the $95 \%$ confidence interval did not contain zero) for four out of five hypotheses. Fig. 3 and Table 5 show a summary of the proposed structural equation model and the mediation results. The $\mathrm{R}^{2}$ values reported in Fig. 3 indicate the explanatory power of the predictor variable for each construct. The credibility of authenticity claims explained $35 \%$ of the variance in perceived restaurant competence $\left(\mathrm{R}^{2}=.354\right)$. Additionally, the credibility of authenticity claims and perceived restaurant competence predicted $59 \%$ of the variance in constructed authenticity $\left(\mathrm{R}^{2}=.588\right)$. Finally, the credibility of authenticity claims, perceived restaurant competence, and constructed authenticity together predicted $49 \%$ of the variance in purchase intention $\left(\mathrm{R}^{2}=.488\right)$. 
[Insert Figure 3 here]

[Insert Table 5 here]

The bootstrapping results showed that the covariate of age had significant effects on perceived competence and purchase intention. Specifically, the older participants perceived higher restaurant competence $(\beta=.187,95 \% \mathrm{CI}=.032$ to $.341, p<.05)$ and had higher purchase intentions $(\beta=.183,95 \% \mathrm{CI}=.035$ to $.331, p<.05)$ than the young participants. The results showed that the credibility of authenticity claims was not related to purchase intention $(\beta=.040,95 \%$ $\mathrm{CI}=-.051$ to .132 , n.s.); thus, $\mathrm{H} 4$ is rejected. Supporting H5 and H6, the credibility of authenticity claims was positively related to perceived competence $(\beta=.504,95 \% \mathrm{CI}=.432$ to $.576, p<.001)$ and perceived authenticity $(\beta=.295,95 \% \mathrm{CI}=.233$ to $.358, p<.001)$.

In addition, perceived competence had a positive effect on perceived authenticity $(\beta=.419,95 \% \mathrm{CI}=.349$ to $.488, p<.001)$ and purchase intention $(\beta=.234,95 \% \mathrm{CI}=.127$ to .341 , $p<.001)$; thus, H7 and H8 are confirmed. Finally, H9 is confirmed by the significant influence of perceived authenticity on purchase intention $(\beta=.552,95 \% \mathrm{CI}=.423$ to $.682, p<.001)$. Both perceived competence (indirect effect: $\beta=.118,95 \% \mathrm{CI}=.056$ to .185 ) and perceived authenticity (indirect effect: $\beta=.163,95 \% \mathrm{CI}=.112$ to .222 ) mediated the effect of the credibility of authenticity claims on purchase intention.

To provide a standardized effect size, the kappa-squared $\left(\kappa^{2}\right)$ for the indirect effect, which represents the proportion of the value of a quantity to its maximum possible value (Preacher and Kelley, 2011, p. 106), was calculated. The standardized effect size of the indirect effect on purchase intention through perceived authenticity $\left(\kappa^{2}=.373,95 \% \mathrm{CI}=.115\right.$ to .232$)$ was greater 
than that through perceived competence $\left(\kappa^{2}=.269,95 \% \mathrm{CI}=.060\right.$ to .197$)$. Additionally, consumers' perceived credibility of authenticity claims influenced their purchase intention through multiple paths: credibility of authenticity claims $\rightarrow$ perceived competence $\rightarrow$ perceived authenticity $\rightarrow$ purchase intention (indirect effect: $\beta=.117,95 \% \mathrm{CI}=.079$ to .159 ). The standardized effect size of this indirect effect was $\kappa^{2}=.266(95 \% \mathrm{CI}=.087$ to .168$)$.

\section{Discussion and conclusions}

\subsection{Theoretical implications}

This study contributes to the hospitality literature in several ways. First, an important theoretical contribution of this study is the development and testing of a conceptual model based on signaling theory and the trust-transfer theory. The adequacy of applying signaling theory to consumer behavior has been assessed in diverse contexts (Atkinson and Rosenthal, 2014; Lohse and Rosen, 2001). However, few studies applied signaling theory in the hospitality and tourism literature. Recently, Filieri et al. (2020) employed signaling theory to explain the moderating role of hotel quality signals in the relationship between extremely negative ratings on consumer review helpfulness. Following this study, the current study utilized signaling theory to examine customers' perceived credibility of a restaurant's authenticity claims.

Signaling theory emphasizes that credibility signals are valuable only when they are interpreted as credible (Atkinson and Rosenthal, 2014). Thus, this study aimed to reveal how customers perceive the credibility of three attributes of authenticity claims that are widely used in practice. The results show that business self-claims of authenticity generated significantly lower credibility than claims by the government and the local community. The finding echoes 
those of previous studies (Cohen and Cohen, 2012; Lugosi, 2016) that government and local residents are significant authenticators of authenticity. In addition, this result corroborates the research finding that commercial sources are generally perceived to be less credible than noncommercial sources (Haley, 1996) such as the government and local residents.

Furthermore, this study found that customers regarded the authenticity claims made by chain organizations as more credible than those made by independent units. This surprising finding contradicts the existing literature on authenticity. For example, Steiner and Reisinger (2006) stated that in Australia, the standardization of products damages the sense of authenticity, indicating that chain organizations are often perceived as inauthentic. Kovács et al. (2014) researched restaurants in U.S. metropolitan areas and found that consumers perceive independent restaurants as being more authentic than chain restaurants. Using Starbucks as an example, the standardization of Starbucks is viewed negatively from the perspective of Europe's indigenous coffeehouse tradition. However, there is no such coffee tradition in China; thus, Chinese consumers search for authenticity from some food chains such as 'western' chains (Henningsen, 2012). In addition, as chain organizations enjoy a positive reputation and image in China (Chow et al., 2007; Wang et al., 2008), Chinese consumers are likely to trust the claims by chain organizations, even when the claims are about restaurant authenticity.

An interesting finding of this study is that the participants showed equal levels of credibility towards the authenticity claims in both short and long history conditions, even though Johnston and Baumann (2007) noted that a long history and tradition is a characteristic of authentic food. A possible reason for this finding could be that the specific number of years that a traditional restaurant has been in operation is not very important once it satisfies a certain threshold (i.e., 25 years, EU, 2006). Similarly, Chen (2016) noted that customers believe that 
traditional restaurants founded in the 1990s can provide authentic dining experiences.

In addition, this study extended the trust-transfer theory by examining trust transfer within the same entity (or organization). Specifically, this study examined the indirect effect of the credibility of authenticity claims on purchase intention through perceived competence and constructed authenticity. In support of the current theorization that the trust transfer process occurs in an intra-channel fashion (Lee et al., 2014), this study found that customers' perceived credibility of authenticity claims had a significant positive influence on their trust in a restaurant's competence and in the perceived authenticity of the restaurant. Furthermore, perceived competence and perceived authenticity determined purchase intention. While Lu et al. (2015) revealed that the effect of authenticity on purchase intention is mediated by other constructs, the existing literature has not developed a good understanding of such mechanism. This finding is consistent with the research that has identified a significant impact of competence (Aaker et al., 2012; Kervyn et al. 2012) and perceived authenticity (Kim and Baker, 2017; Wang and Mattila, 2015; Youn and Kim, 2017) on behavioral intentions. Thus, this study offers solid empirical evidence regarding the relationship among these three constructs and provides an indepth theoretical understanding of trust-transfer within an organization.

However, this study did not find a direct influence of the credibility of authenticity claims on purchase intention. This unexpected finding could be explained by brand-related studies (Homer and Yoon, 1992; Shah et al., 2012) suggesting that consumers' attitudes toward organizational claims influence their behavioral intentions through brand attitudes. This finding implies a nonsignificant direct effect of attitudes toward organizational claims on behavioral intentions. 


\subsection{Managerial implications}

This study provides several managerial implications for the traditional restaurant industry. First, authenticity claims made by the restaurants themselves had a lower impact on consumers' perceived credibility than claims by the government and the local community. Therefore, traditional restaurateurs should minimize the use of self-claims and seek official or non-commercial claims from the government and local residents.

With the popularity of user-generated content online, restaurant practitioners may want to use this powerful informational source by encouraging local people to spread positive word-ofmouth about their restaurants. Restaurant operators could also participate in or organize "best restaurant" competitions in the local area to obtain awards. Industry practitioners could also actively participate in government accreditation schemes to seek official certification. Once these restaurants have obtained acknowledgement from the government or local community, they should proactively promote this acknowledgement in their authenticity claims.

Second, authenticity claims made by chain restaurants are perceived as being more reliable than claims made by independent units, indicating the power of the chain ownership type in influencing consumers' decision-making. Independent traditional restaurants in China that want to expand their business may consider opening other branches, either small or large, to develop a chain ownership type or joining existing restaurant chains to enhance consumers' perceived credibility. Third, because restaurant history does not influence consumers' perceived credibility of authenticity claims and - more importantly - because restaurants cannot change their history, traditional restaurants may minimize the promotion of their history in their authenticity claims.

Fourth, both perceived competence and perceived authenticity were found to significantly 
influence purchase intention. Therefore, restaurant managers should invest effort to create the image that their organizations possess sufficient skills and resources to provide authentic food

and dining experiences. Recently, De Vries and Go (2017) suggested that customers' authenticity perception of a traditional restaurant can be developed by essential (ingredients, traditional recipes, and professional employees) as well as peripheral factors (restaurant name, external façade, food presentation, and interior). Thus, traditional restaurateurs should develop effective cues to convey a feeling of authenticity.

\subsection{Limitations and future research}

This study has several limitations that also constitute future research opportunities. First, this student examined only three attributes of authenticity claims. Specifically, while examining the influence of an official authenticator on perceived credibility, this study focused only on government authenticators. However, other third-party authentication institutes could also make official claims. Thus, further studies could incorporate other types of authenticators into their research. Second, studies show that other factors of organizational claims, such as the quality of the argument, can influence customers' perceived credibility. However, this study did not examine this element, which could be a research topic for further studies.

Third, researchers have found that credibility consists of two main components such as expertise and trustworthiness (Erdem and Swait, 2004). However, this study neglected the expertise dimension and mainly focused on trustworthiness while assessing the credibility of authenticity claims. Thus, a more comprehensive approach would be required in revealing the role of the credibility of authenticity claims.

Fourth, this study examined two types of restaurant ownership but neglected restaurant 
size. Some independent restaurants have a larger size (e.g., venue size) than some chain restaurants, and different chain restaurants may have different economies of scale. Future studies may investigate this factor in their restaurant authenticity models. Finally, this study investigated Chinese citizens and traditional restaurants in China. Thus, the findings may not be applicable to other countries or restaurant contexts. Future studies may replicate this research design in other countries or contexts to verify the study results.

\section{Appendix 1}

Please imagine that you are visiting a city in China and want to try traditional local food. On your journey, you find a restaurant named XYZ. There is a plaque outside the restaurant showing that (the government issued a "traditional restaurant" certificate to this restaurant / this restaurant has been voted a "traditional restaurant" by the local community through an online review website / this restaurant itself claims that it is a "traditional restaurant"). Based on another plaque outside the restaurant, this restaurant is (the only one / a chain restaurant) in China, and this restaurant has a history of 25 years / 250 years. 


\section{References}

Aaker, J., Garbinsky, E.N., Vohs, K.D., 2012. Cultivating admiration in brands: warmth, competence, and landing in the "golden quadrant". Journal of Consumer Psychology 22 (2), 191-194.

Aaker, J., Vohs, K.D., Mogilner, C., 2010. Nonprofits are seen as warm and for-profits as competent: firm stereotypes matter. Journal of Consumer Research 37 (2), 224-237.

Ajzen, I., 2005. Attitudes, Personality, and Behavior. McGraw-Hill Education, UK.

Anderson, J.C., Gerbing, D.W., 1988. Structural equation modeling in practice: a review and recommended two-step approach. Psychological Bulletin 103 (3), 411-423.

Atkinson, L., Rosenthal, S., 2014. Signaling the Green Sell: The Influence of eco-label source, argument specificity, and product involvement on consumer trust. Journal of Advertising 43, 33-45.

Baek, T.H., King, K.W., 2011. Exploring the consequences of brand credibility in services. Journal of Services Marketing 25 (4), 260-272.

Baidu Mobile Testing Centre, 2019. Company website, available at: http://mtc.baidu.com/survey/home/index?from=28-FromDaoHang_7-MTC_10-QSS (accessed 6 January 2019).

Balogh, P., Békési, D., Gorton, M., Popp, J., Lengyel, P., 2016. Consumer willingness to pay for traditional food products. Food Policy 61, 176-184.

Beverland, M.B., 2005. Crafting brand authenticity: the case of luxury wines. Journal of Management Studies 42 (5), 1003-1029.

Beverland, M.B., Lindgreen, A., Vink, M.W., 2008. Projecting authenticity through advertising: Consumer judgments of advertisers' claims. Journal of Advertising 37(1), 5-15. 
Blombäck, A., Brunninge, O., 2009. Corporate identity manifested through historical references. Corporate Communications: An International Journal 14 (4), 404-419.

Boulding, W., Kirmani, A., 1993. A consumer-side experimental examination of signaling theory: Do consumers perceive warranties as signals of quality? Journal of Consumer Research 20, 111-123.

Boush, D.M., Friestad, M., Rose, G.M., 1994. Adolescent skepticism toward TV advertising and knowledge of advertiser tactics. Journal of Consumer Research 21 (1), 165-175.

Carroll, G.R., Torfason, M.T., 2011. Restaurant organizational forms and community in the U.S. in 2005. City and Community 10(1), 1-24.

Castéran, H., Roederer, C., 2013. Does authenticity really affect behavior? The case of the Strasbourg Christmas Market. Tourism Management 36, 153-163.

Chang, C.-T., Tung, M.-H., 2016. Intergenerational appeal in advertising: impacts of brandgender extension and brand history. International Journal of Advertising 35 (2), 345-361.

Chen, R., 2016. A Bite of Nanjing Dapaidang. Retrieved 19 February, 2019, from http://news.winshang.com/html/056/9536.html

Chinese Ministry of Commerce, 2019. The Official Website. Retrieved 2nd December, 2019, from http://zhlzh.mofcom.gov.cn/index.jsp

Chow, H.S.I., Lau, V.P., Lo, W.C.T., Sha, Z.Q., Yun, H., 2007. Service quality in restaurant operations in China: decision- and experiential-oriented perspectives. International Journal of Hospitality Management 26 (3), 698-710.

Cohen, E., Cohen, S.A., 2012. Authentication: hot and cool. Annals of Tourism Research 39 (3), 1295-1314.

Connelly, B.L., Ketchen, D.J., Slater, S.F. (2011). Toward a "theoretical toolbox" for 
sustainability research in marketing. Journal of the Academy of Marketing Science 39 (1), 86-100.

De Vries, H.J., Go, F.M., 2017. Developing a common standard for authentic restaurants. The Service Industries Journal 37, 1008-1028.

Doney, P.M., Cannon, J.P., 1997. An examination of the nature of trust in buyer-seller relationships. Journal of Marketing 61, 35-51.

EU. (2006). Council Regulation (EC) No 509/2006 of 20 March 2006 on agricultural products and foodstuffs as traditional specialties guaranteed. Official Journal of the European Union L 93/1.

Filieri, R., 2016. What makes an online consumer review trustworthy? Annals of Tourism Research 58, 46-64.

Filieri, R., 2015. What makes online reivews helpful? A diagnosticity-adoption framework to explain informational and normative influences in e-WOM. Journal of Business Research $68(6), 1261-1270$.

Filieri, R., Alguezaui, S., McLeay, F., 2015. Why do travelers trust trip advisor? Antecedents of trust towards consumer-generated media and its influence on recommendation adoption and word of mouth. Tourism Management 51, 174-185.

Fornell, C., Larcker, D.F., 1981. Evaluating structural equation models with unobservable variables and measurement error. Journal of Marketing Research 18, 39-50.

Ganesan, S., 1994. Determinants of long-term orientation in buyer-seller relationships. Journal of Marketing 58 (2), 1-19.

Gao, J., Wang, X., 2012. Development and living conditions of Hubei time-honored brand restaurants. Journal of Wuhan Commercial Service College 26 (1), 10-13. 
Gilmore, J.H., Pine, B.J., 2007. Authenticity: What Consumers Really Want. Harvard Business School Press, Boston, MA.

Grayson, K., Martinec, R. 2004. Consumer perceptions of iconicity and indexicality and their influence on assessments of authentic market offerings. Journal of Consumer Research, $31(2), 296-312$.

Hair, J.F., Black, W.C., Babin, B.J., Anderson, R.E., 2010. Multivariate Data Analysis: A Global Perspective. Pearson, Upper Saddle River, NJ.

Haley, E., 1996. Exploring the construct of organization as source: consumers' understandings of organizational sponsorship of advocacy advertising. Journal of Advertising 25 (2), 19-35.

Harris, K.J., DiPietro, R.B., Murphy, K.S., Rivera, G., 2014. Critical food safety violations in Florida: relationship to location and chain vs. non-chain restaurants. International Journal of Hospitality Management 38, 57-64.

Hayes, A.F., 2013. Introduction to Mediation, Moderation, and Conditional Process Analysis: A Regression-Based Approach. Guilford Publications, New York, NY.

Henningsen, L., 2012. Individualism for the masses? Coffee consumption and the Chinese middle class' search for authenticity. Inter-Asia Cultural Studies 13 (3), 408-427.

Highhouse, S., Brooks, M. E., Gregarus, G., 2009. An organizational impression management perspective on the formation of corporate reputations. Journal of Management 35 (6), 1481-1493.

Holbrook, M.B., 1978. Beyond attitude structure: toward the informational determinants of attitude. Journal of Marketing Research 15 (4), 545-556.

Homer, P.M., Yoon, S.-G., 1992. Message framing and the interrelationships among ad-based feelings, affect, and cognition. Journal of Advertising 21 (1), 19-33. 
Hong, I.B., Cho, H., 2011. The impact of consumer trust on attitudinal loyalty and purchase intentions in B2C e-marketplaces: intermediary trust vs. seller trust. International Journal of Information Management 31 (5), 469-479.

Hoorens, V., Pandelaere, M., Oldersma, F., Sedikides, C., 2012. The hubris hypothesis: you can self-enhance, but you'd better not show it. Journal of Personality 80 (5), 1237-1274.

Hu, Y., Sundar, S.S., 2010. Effects of online health sources on credibility and behavioral intentions. Communication Research 37 (1), 105-132.

Jin, G.Z., Leslie, P., 2009. Reputational incentives for restaurant hygiene. American Economic Journal: Microeconomics 1 (1), 237-267.

Johnson, D., Grayson, K., 2005. Cognitive and affective trust in service relationships. Journal of Business Research 58, 500-507.

Johnston, J., Baumann, S., 2007. Democracy versus distinction: A study of omnivorousness in gourmet food writing. American Journal of Sociology 113 (1), 165-204.

Kervyn, N., Fiske, S.T., Malone, C., 2012. Brands as intentional agents framework: how perceived intentions and ability can map brand perception. Journal of Consumer Psychology 22 (2), 166-176.

Kim, J.-H., Jang, S.-C., 2016. Determinants of authentic experiences: an extended Gilmore and Pine model for ethnic restaurants. International Journal of Contemporary Hospitality Management 28 (10), 2247-2266.

Kim, J.-H., Youn, H., Rao, Y., 2017. Customer responses to food-related attributes in ethnic restaurants. International Journal of Hospitality Management 61, 129-139.

Kim, K., Baker, M.A., 2017. The Impacts of service provider name, ethnicity, and menu information on perceived authenticity and behaviors. Cornell Hospitality Quarterly 58, 
$312-318$.

Kim, M.-J., Lee, C.-K., Chung, N., 2013. Investigating the role of trust and gender in online tourism shopping in South Korea. Journal of Hospitality \& Tourism Research 37, 377401.

Kim, S.-B., Kim, D.-Y., 2014. The effects of message framing and source credibility on green messages in hotels. Cornell Hospitality Quarterly 55 (1), 64-75.

Komiak, S.Y., Benbasat, I., 2006. The effects of personalization and familiarity on trust and adoption of recommendation agents. MIS quarterly, 941-960.

Kong, Q., Zheng, S., Zhu, B., Chen, Z., 2009. Research on consumer psychology and behaviour on Beijing famous old brand. Advertising Panorama 5, 24-35.

Kovács, B., Carroll, G.R., Lehman, D.W., 2017. The perils of proclaiming an authentic organizational identity. Sociological Science 4, 80-106.

Kovács, B., Carroll, G.R., Lehman, D.W., 2014. Authenticity and consumer value ratings: Empirical tests from the restaurant domain. Organization science, 25 (2), 458-478.

Kozup, J.C., Creyer, E.H., Burton, S., 2003. Making healthful food choices: the influence of health claims and nutrition information on consumers' evaluations of packaged food products and restaurant menu items. Journal of Marketing 67 (2), 19-34.

Kuan, H.H., Bock, G.W., 2007. Trust transference in brick and click retailers: an investigation of the before-online-visit phase. Information Management 44 (2), 175-187.

Lafferty, B.A., Goldsmith, R.E., Newell, S.J., 2002. The dual credibility model: The influence of corporate and endorser credibility on attitudes and purchase intentions. Journal of Marketing Theory and Practice 10, 1-11.

Lee, C., Hallak, R., Sardeshmukh, S.R., 2016. Drivers of success in independent restaurants: A 
study of the Australian restaurant sector. Journal of Hospitality and Tourism management 29, 99-111.

Lee, K., Lee, Y., Kwon, S., 2015. How nutrition information frame affects parents' perceptions of restaurants: The moderating role of information credibility. International Journal of Hospitality Management 46, 112-119.

Lee, Y.-K., Kim, S., Lee, C.-K., Kim, S.-H., 2014. The Impact of a Mega Event on Visitors' Attitude toward Hosting Destination: Using Trust Transfer Theory. Journal of Travel \& Tourism Marketing 31, 507-521.

Lehman, D.W., Kovács, B., Carroll, G.R., 2018. The beholder's eyes: audience reactions to organizational self-claims of authenticity. Socius 4, 2378023118793030.

Lien, C.H., Cao, Y., 2014. Examining Wechat users' motivations, trust, attitudes, and positive word-of-mouth: Evidence from China. Computers in Human Behavior 41, 104-111.

Lim, Y.-S., Van der Heide, B., 2015. Evaluating the wisdom of strangers: the perceived credibility of online consumer reviews on Yelp. Journal of Computer-Mediated Communication 20 (1), 67-82.

Liu, L., Lee, K.O., Liu, R., Chen, J., 2018. Trust transfer in social media brand communities: The role of consumer engagement. Internatinal Journal of Informatin Mangement 41, 1-13.

Lohse, G.L., Rosen, D.L., 2001. Signaling quality and credibility in yellow pages advertising: The influence of color and graphics on choice. Journal of Advertising 30 (2), 73-83.

Lowry, P. B., Roberts, T. L. Higbee, T., 2007. First impressions with websites: the effect of the familiarity and credibility of corporate logos on perceived consumer swift trust of websites. In International Conference on Human-Computer Interaction (pp. 77-85). 
Springer, Berlin, Heidelberg.

Lu, A.C.C., Gursoy, D., Lu, C.Y., 2015. Authenticity perceptions, brand equity and brand choice intention: the case of ethnic restaurants. International Journal of Hospitality Management $50,36-45$.

Lugosi, P., 2016. Socio-technological authentication. Annals of Tourism Research 58, 100-113.

Luo, C., Luo, X., Schatzberg, L., Sia, C.L., 2013. Impact of informational factors on online recommendation credibility: The moderating role of source credibility. Decision Support Systems, 56, 92-102.

Ma, X., Wei, W., Bai, Y., 2017. Types and mechanism of perceived brand authenticity clues in old brand restaruants: social network analysis on Chinese time-honored restaurants. East China Economic Management 31 (8), 176-184.

Mauri, A.G., Minazzi, R., 2013. Web reviews influence on expectations and purchasing intentions of hotel potential customers. International Journal of Hospitality Management 34, 99-107.

McGinnies, E., Ward, C.D., 1980. Better liked than right: Trustworthiness and expertise as factors in credibility. Personality and Social Psychology Bulletin 6, 467-472.

Meng, B., Choi, K., 2017. Theme restaurants' servicescape in developing quality of life: The moderating effect of perceived authenticity. International Journal of Hospitality Management 65, 89-99.

Mkono, M., 2013. Hot and cool authentication: a netnographic illustration. Annals of Tourism Research 41 (1), 215-218.

Morgan, R.M., Hunt, S.D., 1994. The commitment-trust theory of relationship marketing. Journal of Marketing 58 (3), 20-38. 
Morhart, F., Malär, L., Guèvremont, A., Girardin, F., Grohmann, B., 2015. Brand authenticity: an integrative framework and measurement scale. Journal of Consumer Psychology 25 (2), 200-218.

Moulard, J.G., Garrity, C.P., Rice, D.H., 2015. What makes a human brand authentic? Identifying the antecedents of celebrity authenticity. Psychology \& Marketing 32, 173186.

O'Keefe, D.J., 2002. Persuasion: theory \& research (2nd ed.). Sage Publications, Thousand Oaks, CA.

Peterson, R.A., 2005. In search of authenticity. Journal of Management Studies 42 (5), 10831098.

Portal, S., Abratt, R., Bendixen, M., 2018. The role of brand authenticity in developing brand trust. Journal of Strategic Marketing.

Prahalad, C.K., Hamel, G., 1990. The core competence of the corporation. Harvard Business Review 68 (3), 79-91.

Preacher, K.J., Kelley, K., 2011. Effect size measures for mediation models: Quantitative strategies for communicating indirect effects. Psychological Methods 16, 93-115.

Reich, A.Z., McCleary, K.W., Tepanon, Y., Weaver, P.A. 2005. Roles of product and service quality on brand loyalty: An investigation of quick service restaurants. Journal of Foodservice Business Research 8 (3), 35-53.

Scarpato, R., Daniele, R., 2003. New global cuisine: tourism, authenticity and sense of place in postmodern gastronomy. Food Tourism Around The World: Development, Management and Markets. pp. 296-313.

Shah, S.S.H., Aziz, J., Jaffari, A.R., Waris, S., Ejaz, W., Fatima, M., Sherazi, S.K., 2012. The 
impact of brands on consumer purchase intentions. Asian Journal of Business Management 4 (2), 105-110.

Sims, R., 2009. Food, place and authenticity: local food and the sustainable tourism experience. Journal of Sustainable Tourism 17 (3), 321-336.

Sinha, N., Chaudhuri, H.R., Fowler, J.G., Mazumdar, S., 2018. Market mediated authenticity in culturally themed culinary space. Qual. Mark. Res. Int. J. 3, 353-374.

Song, H., Phan, B.V., Kim, J.-H., 2019. The congruity between social factors and theme of ethnic restaurant: Its impact on customer's perceived authenticity and behavioural intentions. Journal of Hospitality and Tourism management 40, 11-20.

Spence, A.M., 1974. Market Signaling: Informational Transfer in Hiring and Related Screening Processes. Harvard University Press, Cambridge, MA.

Spencer, L.M., Spencer, S.M., 2008. Competence at Work Models for Superior Performance. John Wiley \& Sons, New York, NY.

Spry, A., Pappu, R., Cornwell, B.T. 2011. Celebrity endorsement, brand credibility and brand equity. European Journal of Marketing 45 (6), 882-909.

Steiner, C. J., Reisinger, Y., 2006. Understanding existential authenticity. Annals of Tourism Research, 33 (2), 299-318.

Stewart, K. J. 2003. Trust transfer on the world wide web. Organization Science, 14 (1), 5-17. Taylor, C., 1991. The Ethics of Authenticity. Harvard University Press, London.

Tormala, Z.L., Petty, R.E., 2004. Source credibility and attitude certainty: a metacognitive analysis of resistance to persuasion. Journal of Consumer Psychology 14 (4), 427-442.

Tsai, C.T.S., Lu, P.H., 2012. Authentic dining experiences in ethnic theme restaurants. International Journal of Hospitality Management 31, 304-306. 
Uggioni, P.L., Proença, R.P.d.C., Zeni, L.A.Z.R., 2010. Assessment of gastronomic heritage quality in traditional restaurants. Revista de Nutrição 23, 7-16.

Vanhonacker, F., Lengard, V., Hersleth, M., Verbeke, W., 2010. Profiling European traditional food consumers. British Food Journal 112, 871-886.

Wang, C.Y., Mattila, A.S., 2015. The Impact of servicescape cues on consumer prepurchase authenticity assessment and patronage intentions to ethnic restaurants. Journal of Hospitality \& Tourism Research 39, 346-372.

Wang, N., 1999. Rethinking authenticity in tourism experience. Annals of Tourism Research 26 (2), 349-370.

Wang, N., Shen, X.L., Sun, Y., 2013. Transition of electronic word-of-mouth services from web to mobile context: A trust transfer perspective. Decision Support Systems 54 (3), 13941403.

Wang, Z.J., Zhu, M., Terry, A., 2008. The development of franchising in China. Journal of Marketing Channels 15 (2-3), 167-184.

Wathen, C.N., Burkell, J., 2002. Believe it or not: factors influencing credibility on the web. Journal of the American Society for Information Science Technology 53 (2), 134-144.

Wiedmann, K.-P., Hennigs, N., Schmidt, S., Wuestefeld, T., 2011. Drivers and outcomes of brand heritage: consumers' perception of heritage brands in the automotive industry. Journal of Marketing Theory and Practice 19 (2), 205-220.

Williams, A.M., Baláž, V., 2013. Tourism, risk tolerance and competences: travel organization and tourism hazards. Tourism Management 35, 209-221. 
Xu, W., Wang, X., Liu, W., 2015. The authenticity perception of the concept, dimensions and chracteristics of time-honored brands: a qualitative research based on grounded theory. Collected Essays on Finance and Economics (11), 80-87.

Youn, H., Kim, J.-H., 2017. Effects of ingredients, names and stories about food origins on perceived authenticity and purchase intentions. International Journal of Hospitality Management 63, 11-21.

Young, J.A., Clark, P.W., McIntyre, F.S., 2007. An exploratory comparison of the casual dining experience. Journal of Foodservice Business Research 10 (3), 87-105. 
Fig. 1. Research model

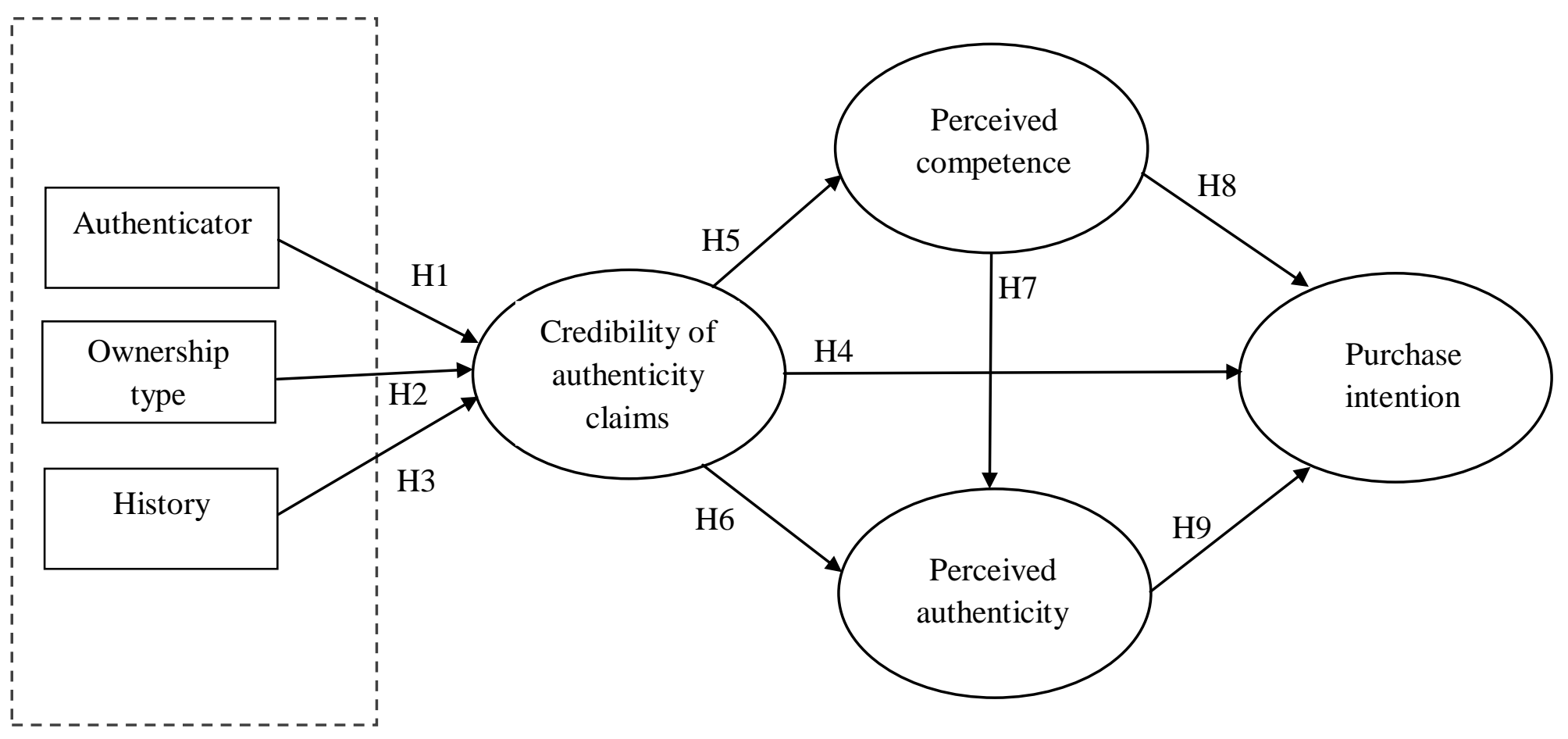


Fig. 2. Interaction effect between ownership type and history on credibility of authenticity claims

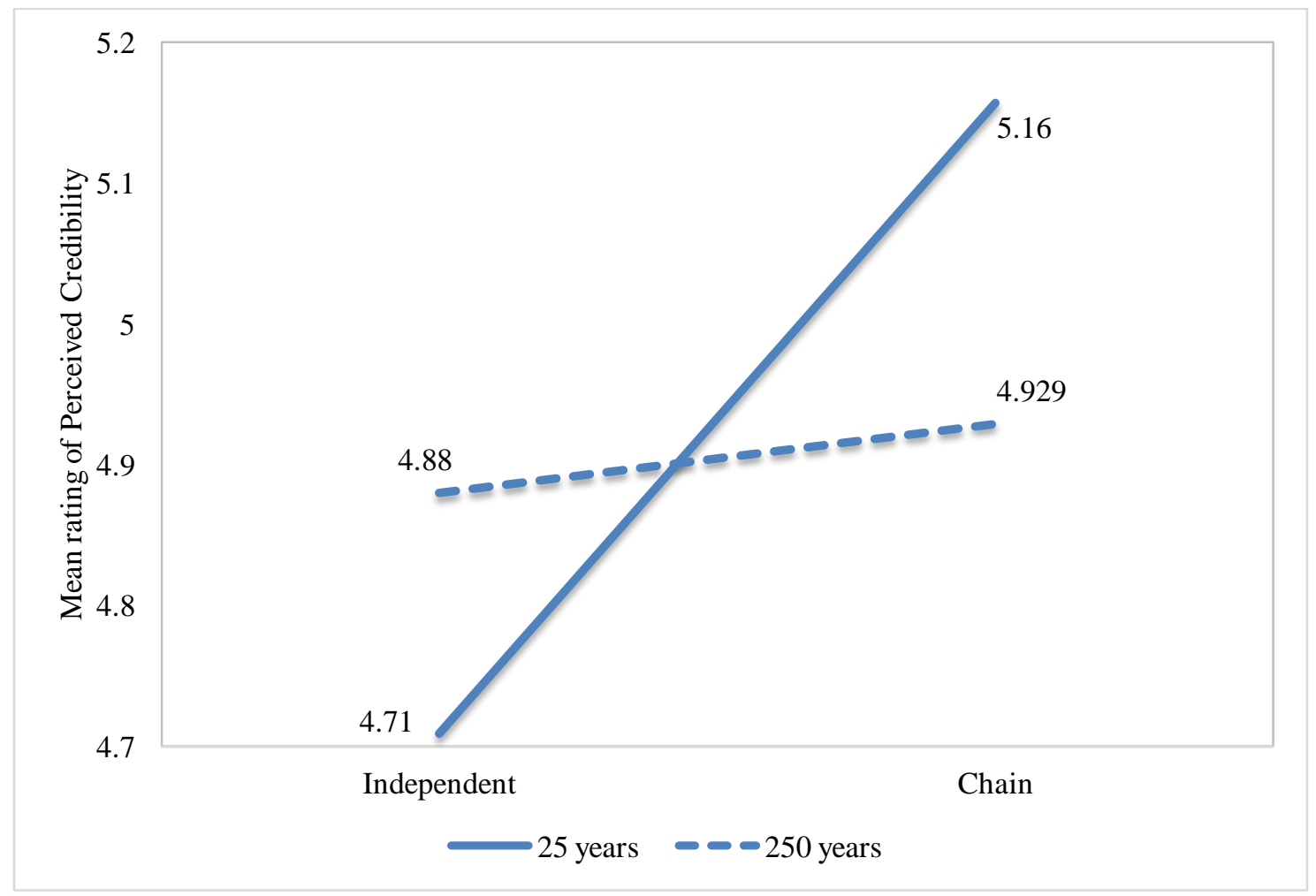


Fig. 3. Results of the structural model

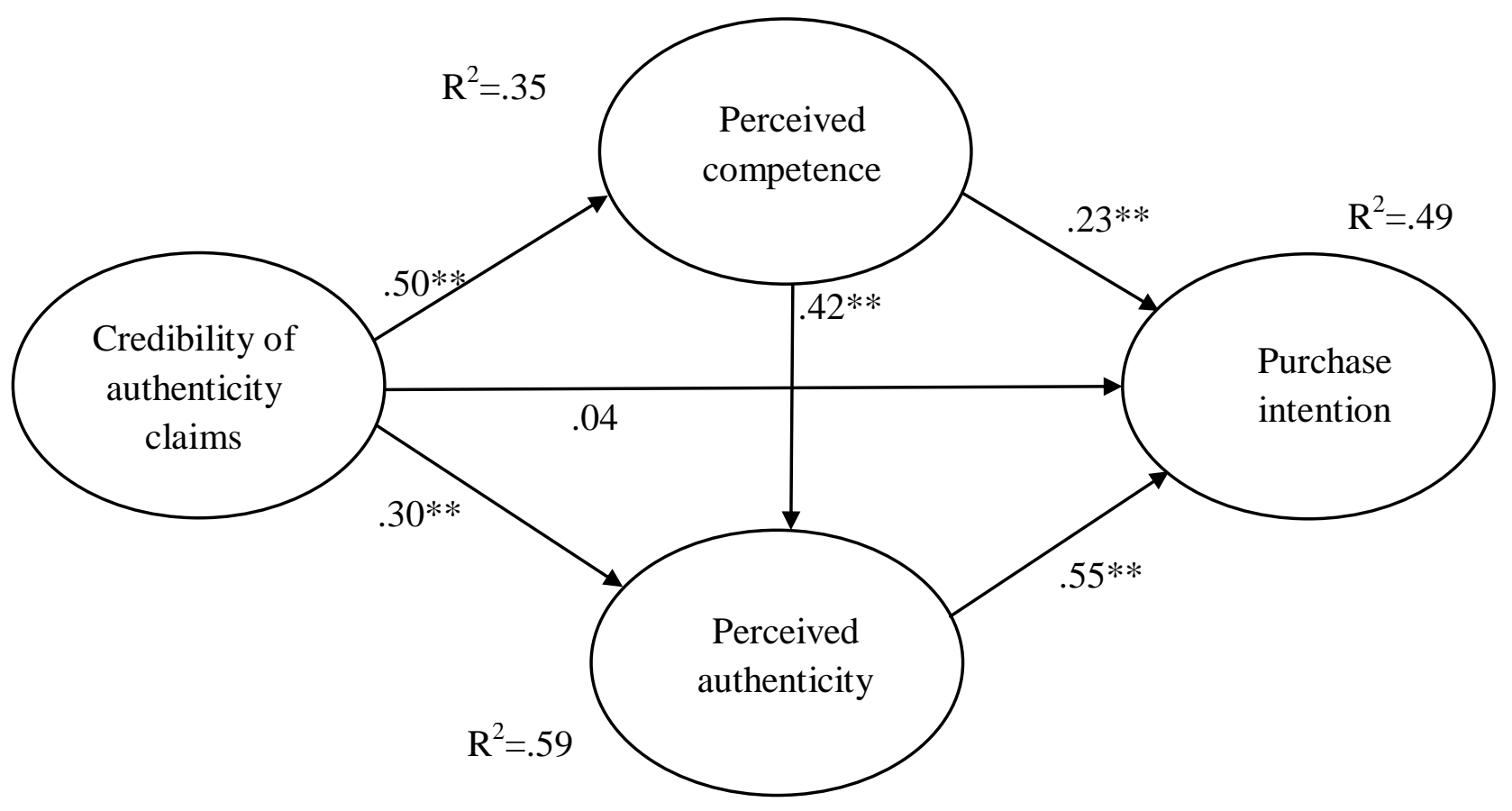

Note: $* p<.05, * * p<.001$ 
Table 1. Summary of significant ANCOVA results for credibility of authenticity claims.

\begin{tabular}{lcccr}
\hline Sources & $S S E$ & $d f$ & $M S E$ & $F$-value \\
\hline Age & 30.675 & 1 & 30.675 & $30.227^{* *}$ \\
Authenticator & 17.690 & 2 & 8.845 & $8.716^{* *}$ \\
Ownership type & 6.085 & 1 & 6.085 & $5.996^{*}$ \\
Ownership type x history & 4.204 & 1 & 4.204 & $4.142^{*}$ \\
\hline
\end{tabular}

Note: $* p<.05, * * p<.001$ 
Table 2. CFA results.

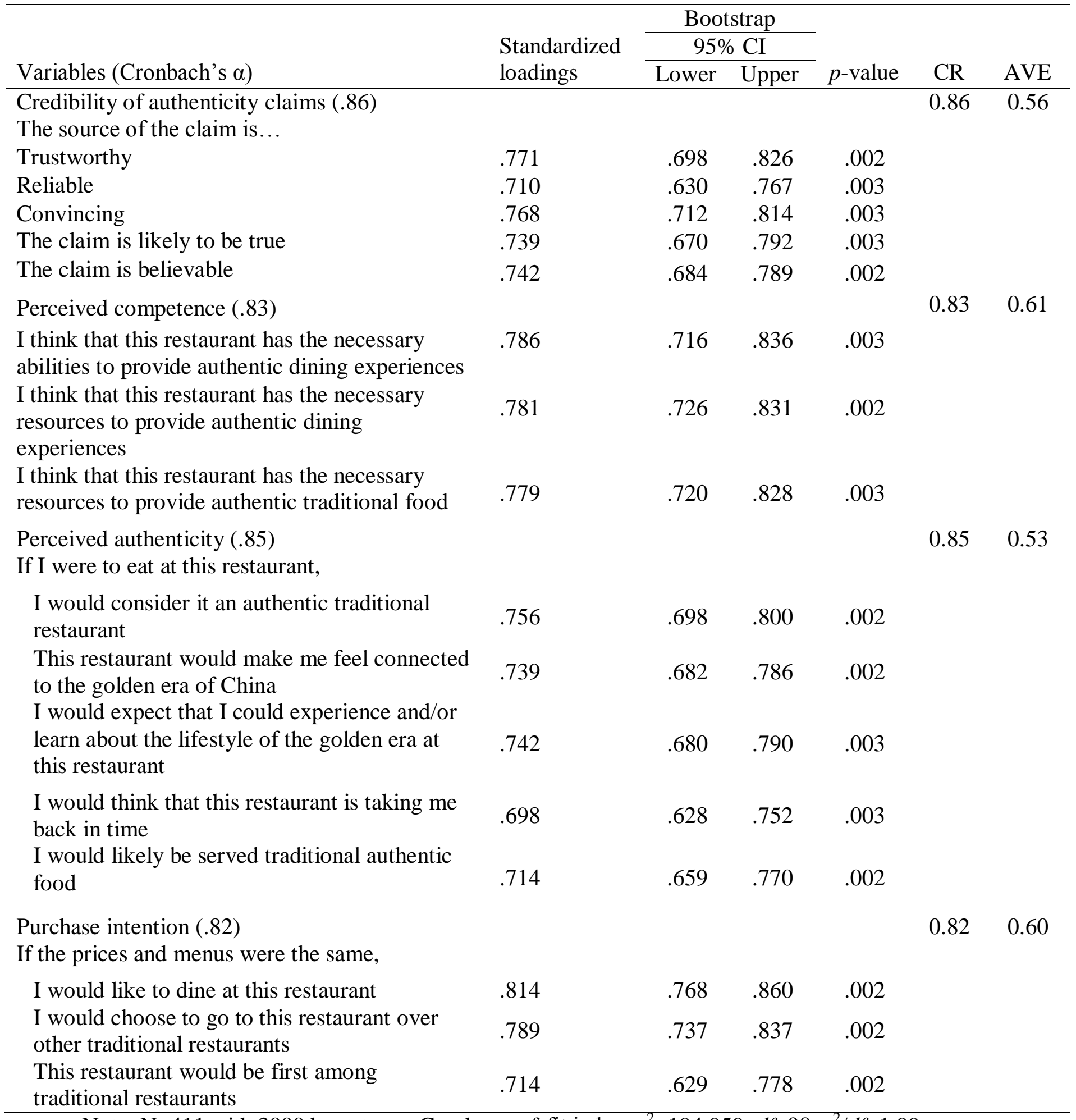

Note: $\mathrm{N}=411$ with 3000 bootstraps. Goodness-of-fit index: $\chi^{2}=194.959, d f=98, \chi^{2} / d f=1.99$, $\mathrm{CFI}=.971, \mathrm{TLI}=.965, \mathrm{IFI}=.972, \mathrm{RMSEA}=.049 . \mathrm{CI}=$ confidence interval, $\mathrm{CR}=$ composite reliability, AVE=average variance extracted. 
Table 3. Construct intercorrelations.

\begin{tabular}{|c|c|c|c|c|c|c|}
\hline Constructs & CR & $\mathrm{PC}$ & $\mathrm{PA}$ & PI & $\mathrm{M}$ & SD \\
\hline$\overline{C R}$ & $.56^{\mathrm{a}}$ & & & & 4.92 & 1.05 \\
\hline PC & $.35^{\mathrm{b}}$ & $.61^{\mathrm{a}}$ & & & 5.12 & .96 \\
\hline PA & $.44^{\mathrm{b}}$ & $.49^{\mathrm{b}}$ & $.53^{\mathrm{a}}$ & & 5.19 & .85 \\
\hline PI & $.24^{\mathrm{b}}$ & $.35^{\mathrm{b}}$ & $.45^{\mathrm{b}}$ & $.60^{\mathrm{a}}$ & 5.38 & 1.01 \\
\hline
\end{tabular}

Note: $\mathrm{CR}=$ credibility of authenticity claims; $\mathrm{PC}=$ perceived competence; $\mathrm{CA}=$ perceived authenticity; PI=purchase intention. ${ }^{\mathrm{a}}$ Average variance extracted; ${ }^{\mathrm{b}}$ squared correlations. 
Table 4. Results of model comparisons.

\begin{tabular}{llcccccc}
\hline Models & Chi-square/df & $\Delta \chi 2$ & CFI & NFI & IFI & TLI & RMSEA \\
\hline Research model & $160.287 / 97=1.652$ & - & .981 & .954 & .981 & .977 & .040 \\
Full mediation model & $165.070 / 98=1.684$ & $4.783(<.05)$ & .980 & .953 & .980 & .976 & .041 \\
Alternative model 1 & $193.915 / 98=1.979$ & $33.628(<.001)$ & .972 & .945 & .972 & .965 & .049 \\
Alternative model 2 & $195.961 / 99=1.979$ & $35.674(<.001)$ & .971 & .944 & .972 & .965 & .049 \\
\hline
\end{tabular}

Note:

Full mediation model: full model with no direct path from credibility of authenticity claims to purchase intention

Alternative model 1: The path of H6 (credibility of authenticity claims $\rightarrow$ perceived authenticity) was constrained to zero.

Alternative model 2: The paths of $\mathrm{H} 4$ (credibility of authenticity claims $\rightarrow$ purchase intention) and H6 (credibility of authenticity claims $\rightarrow$ perceived authenticity) were constrained to zero. 
Table 5. Mediation results.

\begin{tabular}{|c|c|c|c|}
\hline Predictor & $\begin{array}{c}\text { Perceived } \\
\text { Competence }\end{array}$ & $\begin{array}{c}\text { Perceived } \\
\text { Authenticity }\end{array}$ & $\begin{array}{l}\text { Purchase } \\
\text { Intention }\end{array}$ \\
\hline Age & $.187(.08)^{*}$ & $.101(.056)$ & $.183(.075)^{*}$ \\
\hline Credibility of authenticity claims & $.504(.04)^{* *}$ & $.295(.032)^{* *}$ & $.040(.046)$ \\
\hline Perceived competence & - & $.419(.035)^{* *}$ & $.234(.054) * *$ \\
\hline Perceived authenticity & - & - & $.552(.066)^{* *}$ \\
\hline$R^{2}$ & $.35^{* *}$ & $.59 * *$ & $.49 * *$ \\
\hline Indirect effect on purchase intention & Effect (SE) & LL $95 \% \mathrm{CI}$ & UL $95 \% \mathrm{CI}$ \\
\hline $\mathrm{CR} \rightarrow \mathrm{PC} \rightarrow \mathrm{PI}$ & $.118(.03)$ & .056 & .185 \\
\hline $\mathrm{CR} \rightarrow \mathrm{PA} \rightarrow \mathrm{PI}$ & $.163(.03)$ & .112 & .222 \\
\hline $\mathrm{CR} \rightarrow \mathrm{PC} \rightarrow \mathrm{PA} \rightarrow \mathrm{PI}$ & $.117(.02)$ & .079 & .159 \\
\hline Kappa-square for the indirect effect & Effect (SE) & LL 95\% CI & UL 95\% CI \\
\hline $\mathrm{CR} \rightarrow \mathrm{PC} \rightarrow \mathrm{PI} \quad\left(\kappa^{2}\right)$ & $.269(.04)$ & .060 & .197 \\
\hline $\mathrm{CR} \rightarrow \mathrm{PA} \rightarrow \mathrm{PI}\left(\kappa^{2}\right)$ & $.373(.03)$ & .115 & .232 \\
\hline $\mathrm{CR} \rightarrow \mathrm{PC} \rightarrow \mathrm{PA} \rightarrow \mathrm{PI}\left(\kappa^{2}\right)$ & $.266(.02)$ & .087 & .168 \\
\hline
\end{tabular}

Note: $\mathrm{CR}=$ credibility of authenticity claims; $\mathrm{PC}=$ perceived competence; $\mathrm{CA}=$ constructed authenticity; PI=purchase intention; LL=lower limit; UL=upper limit; standard errors in parentheses; bootstrap sample size $=3000 .{ }^{*} p<.05 ;{ }^{*} p<.001$. 